\title{
Usefulness of baseline lipids and C-reactive protein in women receiving menopausal hormone therapy as predictors of treatment-related coronary events.
}

\author{
Paul Bray \\ Thomas Jefferson University \\ Joseph C Larson \\ Fred Hutchinson Cancer Research Center \\ Andrea Z Lacroix \\ Fred Hutchinson Cancer Research Center \\ Bo/mu thlalasdaradditional works at: https://jdc.jefferson.edu/cardeza_foundation \\ Zgham and Women's Hospital, Harvard Medical School \\ Part of the Hematology Commons \\ Merangstiknadow how access to this document benefits you \\ University of Florida, Gainseville
}

\section{Recommended Citation}

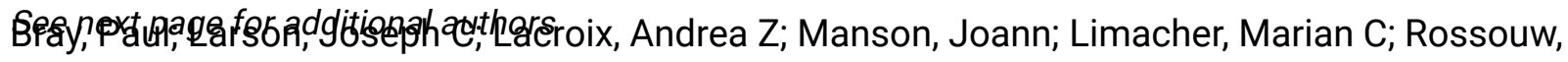
Jacques E; Lasser, Norman L; Lawson, William E; Stefanick, Marcia L; Langer, Robert D; and Margolis, Karen L, "Usefulness of baseline lipids and C-reactive protein in women receiving menopausal hormone therapy as predictors of treatment-related coronary events." (2008).

Cardeza Foundation for Hematologic Research. Paper 14.

https://jdc.jefferson.edu/cardeza_foundation/14

This Article is brought to you for free and open access by the Jefferson Digital Commons. The Jefferson Digital Commons is a service of Thomas Jefferson University's Center for Teaching and Learning (CTL). The Commons is a showcase for Jefferson books and journals, peer-reviewed scholarly publications, unique historical collections from the University archives, and teaching tools. The Jefferson Digital Commons allows researchers and interested readers anywhere in the world to learn about and keep up to date with Jefferson scholarship. This article has been accepted for inclusion in Cardeza Foundation for Hematologic Research by an authorized administrator of the Jefferson Digital Commons. For more information, please contact: JeffersonDigitalCommons@jefferson.edu. 


\section{Authors}

Paul Bray, Joseph C Larson, Andrea Z Lacroix, Joann Manson, Marian C Limacher, Jacques E Rossouw, Norman L Lasser, William E Lawson, Marcia L Stefanick, Robert D Langer, and Karen L Margolis 


\title{
Usefulness of Baseline Lipids and C-Reactive Protein in Women Receiving Menopausal Hormone Therapy as Predictors of Treatment-Related Coronary Events
}

\author{
Paul F. Bray, MDa, ${ }^{\star}$, Joseph C. Larson, MS ${ }^{\mathrm{b}}$, Andrea Z. LaCroix, MPH, PhD ${ }^{\mathrm{b}}$, JoAnn \\ Manson, MD, DrPH ${ }^{c}$, Marian C. Limacher, MD $^{d}$, Jacques E. Rossouw, MD $^{\mathrm{e}}$, Norman L. \\ Lasser, MD, PhDf, William E. Lawson, MDg, Marcia L. Stefanick, PhD ${ }^{h}$, Robert D. Langer, \\ MD, MPH', and Karen L. Margolis, MD ${ }^{j}{ }^{\dagger}$ for the Women's Health Initiative Investigators \\ aThe Cardeza Foundation for Hematologic Research and Jefferson Medical College, \\ Philadelphia, Pennsylvania ${ }^{b}$ Fred Hutchinson Cancer Research Center, Seattle, Washington \\ 'Brigham and Women's Hospital, Harvard Medical School, Boston, Massachusetts dUniversity of \\ Florida, Gainseville, Florida eProgram Office, National Heart, Lung and Blood Institute, Bethesda, \\ Maryland fPreventive Cardiology Program, New Jersey Medical School, Newark, New Jersey \\ gDivision of Cardiovascular Medicine, State University of New York, Stoney Brook, New York \\ h Stanford Center for Research in Disease Prevention, Stanford University, Palo Alto, California \\ 'Geisinger Center for Health Research, Danville, Pennsylvania UUniversity of Minnesota, \\ Minneapolis, Minnesota
}

\section{Abstract}

\begin{abstract}
Blood lipids and high sensitivity C-reactive protein (hsCRP) are altered by hormone therapy. The goal of the current study was to determine whether lipids and hsCRP have predictive value for hormone therapy benefit or risk for coronary heart disease (CHD) events in postmenopausal women without previous cardiovascular disease. A nested case-control study was performed in the Women's Health Initiative hormone trials. Baseline lipids and hsCRP were obtained from 271 incident CHD cases and 707 controls. In a combined trial analysis, a favorable lipid status at baseline tended to predict better CHD outcomes when taking conjugated equine estrogen (CEE) with or without medroxyprogesterone acetate (MPA). Women with a low density lipoprotein (LDL)/high density lipoprotein (HDL) ratio $<2.5$ had no increase in risk of CHD when taking CEE with or without MPA (OR 0.60, 95\% CI=0.34-1.06), whereas women with an LDL/HDL ratio $\geq 2.5 \mathrm{had}$ an increased risk of CHD (OR 1.73, 95\% CI $=1.18-2.53)(\mathrm{p}$-value for interaction $=0.02)$. Low hsCRP levels added marginally to the value of LDL/HDL $<2.5$ when predicting CHD benefit on hormone therapy. In conclusion, postmenopausal women with undesirable lipid levels had excess CHD risk when using CEE with or without MPA; however, women with favorable lipid levels, especially an LDL/HDL ratio < 2.5, did not have an elevated risk of CHD with CEE with or without MPA, irrespective of hsCRP levels.
\end{abstract}

(C) 2008 Excerpta Medica, Inc. All rights reserved.

"Corresponding author: Tel: 215-955-8544, Fax: 215-955-9170, paul.bray@ jefferson.edu, Jefferson Medical College, 1015 Walnut, Suite 705, Philadelphia, PA, USA.

†A list of Women's Health Initiative investigators is provided in a supplemental file.

ClinicalTrials.gov: NCT00000611

Publisher's Disclaimer: This is a PDF file of an unedited manuscript that has been accepted for publication. As a service to our customers we are providing this early version of the manuscript. The manuscript will undergo copyediting, typesetting, and review of the resulting proof before it is published in its final citable form. Please note that during the production process errors may be discovered which could affect the content, and all legal disclaimers that apply to the journal pertain. 


\section{Keywords}

CHD; hormone therapy; lipids; cholesterol

It remains uncertain whether routinely available CHD biomarkers, such as lipids and hsCRP, may help to identify women at higher or lower risk of incident coronary events mediated by menopausal hormone therapy. The WHI conducted 2 clinical trials, assessing the effect of CEE alone in women without a uterus or CEE+MPA in postmenopausal women who had not undergone hysterectomy. Neither Women's Health Initiative trial showed an overall protective effect of hormone therapy for coronary events, ${ }^{1,2}$ in contrast to results of earlier observational studies. ${ }^{3,4}$ The reasons for this discrepancy are not yet determined but may be related to differences in baseline CHD risks of the study populations and the distributions of risk factors such as lipids and hsCRP. Because clinical trials have demonstrated a small overall increase in the absolute risk of short term hormone therapy use for CHD events in postmenopausal women, we asked whether commonly utilized biomarkers (lipids and hsCRP) could be useful for predicting hormone therapy-mediated CHD risk. We performed a nested case-control study of biomarkers obtained at baseline and 1 year follow-up in women from both WHI hormone trials. The goal of this study was to determine whether baseline lipids and hsCRP have predictive value for hormone therapy benefit or risk for CHD events.

\section{Methods}

Eligibility criteria and recruitment methods have been published for both Women's Health Initiative clinical trials ${ }^{5-7}$ From September 1993 to October 1998 generally healthy postmenopausal women aged 50 to 79 years were enrolled in 40 US clinical centers. Study participants provided informed consent via forms approved by each center's institutional review board. Eligible women with an intact uterus $(n=16,608)$ were randomly assigned to receive $0.625 \mathrm{mg} / \mathrm{d}$ of CEE plus $2.5 \mathrm{mg} / \mathrm{d}$ MPA or a matching placebo. Eligible women who had undergone hysterectomy $(n=10,739)$ were randomly assigned to receive $0.625 \mathrm{mg} / \mathrm{d}$ of CEE or a matching placebo.

A case-control biomarker study was nested within the 2 hormone clinical trials (note that lipid and hsCRP levels were performed only in a subset of participants in these trials). The current study represents a nested case-control analysis of biomarkers in 271 incident CHD cases and 707 controls. Reasoning that future hormone therapy use is likely to be discouraged for women with pre-existing cardiovascular disease, we included only those women without baseline cardiovascular disease. Outcome definitions and methods for ascertaining, documenting, and classifying outcomes have been published. ${ }^{8}$ Women with a history of myocardial infarction, angina, coronary revascularization or stroke prior to study entry were excluded. Cases were defined as all incident acute myocardial infarction requiring overnight hospitalization and/or CHD death in either clinical trial that occurred in the first 4 years of follow-up. Incident myocardial infarction is defined as a clinical myocardial infarction presenting with chest discomfort, typical ECG changes, and elevation of cardiac-specific enzymes, and does not include silent or possible silent myocardial infarctions. Case status was determined by central adjudication based on review of medical records. Controls are defined as women who did not experience a cardiovascular disease event during the entire duration of follow-up in the Women's Health Initiative clinical trial. The case/control selection process was done matching age at screening, randomization date and hysterectomy status. 
Baseline and year 1 blood samples were obtained in a fasting state. The specimens were centrifuged, serum and plasma was frozen at $-70^{\circ} \mathrm{C}$, and shipped on dry ice to a central processing facility. Subjects who became cases within the first year of follow-up did not have their year 1 biomarkers measured. Lipids were measured in ethylenediaminetetraacetic acid -anticoagulated plasma at PPD Global Central Labs (Highland Heights, KY), formerly Medical Research Laboratories International, on a Hitachi 747 General Chemistry Analyzer. Triglycerides were measured by a chromogenic reaction after hydrolysis and oxidation. Total cholesterol was measured enzymatically utilizing cholesterol esterase and cholesterol oxidase. HDL cholesterol was measured after removal of chylomicrons, very low density lipoproteins and LDL from the plasma. LDL-cholesterol was calculated using the Friedewald formula (total cholesterol-HDL cholesterol-triglyceride/5). Lipoprotein(a) levels were measured by an enzyme immunoassay. hsCRP was measured in serum using the Dade Behring N Latex High Sensitivity hsCRP ${ }^{\mathrm{TM}}$ mono assay on the Behring Nephelometer II according to manufacturer's recommendations.

Means and frequencies are presented for demographic data. CHD cases and controls were compared using a 2-sample t-test (continuous variables) or a Chi-Square test (categorical variables). To account for the skewed distribution of the biomarker data, geometric means and standard deviations were calculated for the individual markers. For the ratio variables, which are normally distributed, standard means and deviations were calculated. Testing for descriptive tables was based on a t-test using the logged distribution for the individual biomarkers. All modeling was logistic with both odds ratios and p-values presented in the resulting tables. Interaction models were also fitted using logistic regression including terms for the main effects of the biomarker level of interest (e.g., high LDL/HDL ratio), treatment assignment, and their interaction. The resulting $\mathrm{p}$-value for the interaction term is presented in the tables. All models were adjusted for age, year of randomization, history of hypertension (defined as self-report of pill usage or measured systolic blood pressure $\geq 140$ or diastolic blood pressure 290 ), body mass index, current smoking, self report of cholesterol-lowering medication use, and self-report of treated diabetes. Additional logistic models were run to examine the linear trend of combinations of LDL/HDL ratio and hsCRP on CHD, assigning values to each LDL/HDL ratio and hsCRP combination. All analyses were conducted using SAS 9.1 (SAS Institute, Cary, NC).

\section{Results}

Table 1 shows the baseline characteristics of the study subjects separated by clinical trial and for the trials combined. Increased BMI, current smoking, treated diabetes, and selfreported hypertension predicted case status in the combined trials. Mean baseline values for all biomarkers tended toward a "less desirable" direction in the women in the CEE trial compared to the women in the CEE+MPA trial, but only the mean triglyceride, lipoprotein(a) and hsCRP levels were significantly different between the 2 trials (Table 2). All biomarkers shown in Table 2 except lipoprotein(a) were associated with CHD risk, but the strength of the association varied by treatment group and clinical trial (see online Supplemental Tables).

We examined whether there were associations between the hormone therapy effect on incident CHD and the level of each lipid biomarker or hsCRP (Table 3). Subjects were grouped by desirable or undesirable HDL-cholesterol and triglyceride levels using ATP III recommended cut-offs, ${ }^{9}$ and the median biomarker level of healthy controls for LDLcholesterol, non-HDL-cholesterol, Lp(a) and the total cholesterol (TC)/HDL and triglyceride/HDL ratios. The cut-off for the LDL/HDL ratio was based on desirable values of 100 and 40, respectively. Women with higher levels of LDL-cholesterol, and the total cholesterol/HDL and LDL/HDL ratios had elevated risks of CHD when using CEE+MPA, 
while women with lower levels of these biomarkers did not. A similar trend was observed for the LDL/HDL ratio in the CEE trial. When the trials were combined, there was a significant interaction between HT and the biomarker for LDL-cholesterol, non-HDLcholesterol, the total cholesterol/HDL ratio and the LDL/HDL ratio. hsCRP showed a significant interaction with CEE alone but not CEE+MPA.

We utilized the baseline LDL/HDL ratio biomarker in combination with hsCRP in a combined trial analysis to evaluate CHD risk due to hormone therapy (Table 4). Women who had low LDL/HDL ratios at baseline did not experience an increased risk of CHD events on hormone therapy, regardless of hsCRP level, whereas women with elevated LDL/ HDL ratios had increased risks of hormone therapy-mediated CHD, regardless of hsCRP levels.

\section{Discussion}

This study was designed to assess whether routinely available CHD biomarkers were useful for predicting the risk of incident myocardial infarction and/or CHD death in postmenopausal women without cardiovascular disease who had initiated CEE with or without MPA. The major findings were that several baseline lipid measurements, but especially the LDL/HDL ratio, interact with CEE with or without MPA to modify the risk for CHD. Specifically, women with baseline LDL/HDL ratios above 2.5 were at an increased CHD risk due to CEE with or without MPA, whereas there was no increased CHD risk due to CEE with or without MPA when the baseline LDL/HDL ratio was less than 2.5. We also found evidence that hsCRP added little or no additional predictive value beyond the LDL/HDL biomarker for predicting CHD risk for women using hormone therapy.

Women with baseline HDL-cholesterol $<50$, or with LDL-cholesterol, total cholesterol/HDL ratio and LDL/HDL ratio above the median control value, were at increased CHD risk when assigned to CEE+MPA, and similar trends were observed with unopposed CEE. Importantly, we found no clear evidence that either form of hormone therapy posed a risk for CHD events for women with baseline HDL-cholesterol 250 , or with LDL-cholesterol, total cholesterol/HDL ratio and LDL/HDL ratio below the median control value. When analyzed using median control values for HDL and trigyceride (53 and 135, respectively) instead of the ATP III recommended cutoffs (50 and 150, respectively), the results were essentially the same.

Our analysis has provided a side-by-side comparison of the effect of biomarkers in the 2 Women's Health Initiative hormone trials. The odds ratios for the treatment effect by baseline LDL-cholesterol, HDL-cholesterol, non-HDL-cholesterol, the total cholesterol/ HDL ratio and the LDL/HDL ratio were similar for both the CEE+MPA and CEE clinical trials. These similar responses provide support for combining the 2 trials in the analyses of these latter biomarkers. In the combined Women's Health Initiative hormone trial analysis, with an LDL/HDL ratio $<2.5$ the OR for hormone therapy effect of 0.6 (95\% CI=0.34-1.06), underscoring the potential CHD safety of hormone therapy in women with a desirable, "healthy" lipid profile. These results were not materially affected when women using cholesterol-lowering drugs were excluded from the analyses (data not shown).

How might lipids and hormone therapy interact mechanistically to affect the risk for CHD? There is strong animal data that estrogen is cardioprotective in hyperlipidemic animals when administered at the time of menopause and/or prior to the development of atherosclerosis ${ }^{10}$. Our study specifically excluded women with prior CHD, yet we still observed an interaction between hormone therapy and baseline cholesterol levels for CHD risk even after adjusting for age. Recently, the cholesterol metabolite, 27-hydroxycholesterol, has been shown to 
compete with estrogen for binding to vascular estrogen receptors, blocking the beneficial effects of estrogen (nitric oxide production and endothelial cell migration) on murine vascular cells ${ }^{11}$. This study by Umetani et al. suggests an attractive and testable hypothesis: that postmenopausal women with a poor lipid profile have elevated levels of 27hydroxycholesterol, which disables a potential vascular benefit of estrogen. Conversely, the women in the Women's Health Initiative clinical trials with favorable lipids might experience no harm or even benefit from estrogen therapy if they have low levels of 27hydroxycholesterol.

Since elevated plasma triglyceride levels are thought to be a risk factor for CHD in women ${ }^{12}$ and hormone therapy increases triglyceride levels, it was important to consider the relationship between triglyceride and hormone therapy for CHD events. Our analyses showed high baseline levels of triglyceride were associated with CHD cases in only the CEE +MPA trial, but not the CEE trial (online supplemental data), but we observed no interaction between baseline triglyceride and CEE with or without MPA for CHD events. We also assessed whether the year 1 triglyceride levels or the change from baseline to year 1 triglyceride level were related to developing CHD events, but found no relationship.

The difference in study design between the current biomarker study and the overall Women's Health Initiative hormone trials should be noted. Only women developing CHD events within the first 4 years comprised cases for this biomarker study, and later events were not analyzed. Any conclusions from the current report only pertain to this time frame. Although this study is comparable in size to other large biomarker studies, the planned subgroup analysis nevertheless had relatively small numbers of cases, and we did not have a sufficient sample size to stratify by age.

Despite increasing information and understanding of the clinical benefits and risks of hormone therapy, practitioners are still challenged in making management choices for individual postmenopausal women. The Framingham risk prediction model specifically did not include estrogen replacement therapy use in formulating CHD risk assessment, ${ }^{13}$ and no convincing data has previously defined whether hormone therapy modifies the CHD risk associated with increased lipid levels (or other biomarkers). This report has just considered the risks and benefits associated with CHD outcomes, and the decision to use postmenopausal hormones must consider the totality of health risks and benefits, including stroke, thrombosis and gall bladder disease. Women considering the use of postmenopausal hormone therapy should determine their overall cardiac risk and specifically their lipid profile. The absolute excess CHD risk is low or absent in younger women who take CEE with or without MPA. ${ }^{14}$ Our study provides support that CEE with or without MPA may not increase the short term CHD risk among women with a favorable lipid profile.

\section{Acknowledgments}

The Women's Health Initiative program is funded by the National Heart, Lung and Blood Institute, U.S. Department of Health and Human Services.

\section{References}

1. Manson JE, Hsia J, Johnson KC, Rossouw JE, Assaf AR, Lasser NL, Trevisan M, Black HR, Heckbert SR, Detrano R, Strickland OL, Wong ND, Crouse JR, Stein E, Cushman M. Estrogen plus progestin and the risk of coronary heart disease. N Engl J Med. 2003; 349:523-534. [PubMed: 12904517]

2. Hsia J, Langer RD, Manson JE, Kuller L, Johnson KC, Hendrix SL, Pettinger M, Heckbert SR, Greep N, Crawford S, Eaton CB, Kostis JB, Caralis P, Prentice R. Conjugated equine estrogens and 
coronary heart disease: the Women's Health Initiative. Arch Intern Med. 2006; 166:357-365. [PubMed: 16476878]

3. Rich-Edwards JW, Manson JE, Hennekens CH, Buring JE. The primary prevention of coronary heart disease in women. N Engl J Med. 1995; 332:1758-1766. [PubMed: 7760894]

4. Grady D, Rubin SM, Petitti DB, Fox CS, Black D, Ettinger B, Ernster VL, Cummings SR. Hormone therapy to prevent disease and prolong life in postmenopausal women. Ann Intern Med. 1992; 117:1016-1037. [PubMed: 1443971]

5. The Women's Health Initiative Study Group. Design of the Women's Health Initiative clinical trial and observational study. Control Clin Trials. 1998; 19:61-109. [PubMed: 9492970]

6. Rossouw JE, Anderson GL, Prentice RL, LaCroix AZ, Kooperberg C, Stefanick ML, Jackson RD, Beresford SA, Howard BV, Johnson KC, Kotchen JM, Ockene J. Risks and benefits of estrogen plus progestin in healthy postmenopausal women: principal results From the Women's Health Initiative randomized controlled trial. JAMA. 2002; 288:321-333. [PubMed: 12117397]

7. Anderson GL, Limacher M, Assaf AR, Bassford T, Beresford SA, Black H, Bonds D, Brunner R, Brzyski R, Caan B, Chlebowski R, Curb D, Gass M, Hays J, Heiss G, Hendrix S, Howard BV, Hsia J, Hubbell A, Jackson R, Johnson KC, Judd H, Kotchen JM, Kuller L, LaCroix AZ, Lane D, Langer RD, Lasser N, Lewis CE, Manson J, Margolis K, Ockene J, O’Sullivan MJ, Phillips L, Prentice RL, Ritenbaugh C, Robbins J, Rossouw JE, Sarto G, Stefanick ML, Van Horn L, Wactawski-Wende J, Wallace R, Wassertheil-Smoller S. Effects of conjugated equine estrogen in postmenopausal women with hysterectomy: the Women's Health Initiative randomized controlled trial. JAMA. 2004; 291:1701-1712. [PubMed: 15082697]

8. Curb JD, McTiernan A, Heckbert SR, Kooperberg C, Stanford J, Nevitt M, Johnson KC, ProulxBurns L, Pastore L, Criqui M, Daugherty S. Outcomes ascertainment and adjudication methods in the Women's Health Initiative. Ann Epidemiol. 2003; 13:S122-S128. [PubMed: 14575944]

9. Grundy SM, Brewer HB Jr, Cleeman JI, Smith SC Jr, Lenfant C. Definition of metabolic syndrome: Report of the National Heart, Lung, and Blood Institute/American Heart Association conference on scientific issues related to definition. Circulation. 2004; 109:433-438. [PubMed: 14744958]

10. Hodgin JB, Maeda N. Minireview: estrogen and mouse models of atherosclerosis. Endocrinology. 2002; 143:4495-4501. [PubMed: 12446574]

11. Umetani M, Domoto H, Gormley AK, Yuhanna IS, Cummins CL, Javitt NB, Korach KS, Shaul PW, Mangelsdorf DJ. 27-Hydroxycholesterol is an endogenous SERM that inhibits the cardiovascular effects of estrogen. Nat Med. 2007; 13:1185-1192. [PubMed: 17873880]

12. Hokanson JE, Austin MA. Plasma triglyceride level is a risk factor for cardiovascular disease independent of high-density lipoprotein cholesterol level: a meta-analysis of population-based prospective studies. J Cardiovasc Risk. 1996; 3:213-219. [PubMed: 8836866]

13. Wilson PW, D'Agostino RB, Levy D, Belanger AM, Silbershatz H, Kannel WB. Prediction of coronary heart disease using risk factor categories. Circulation. 1998; 97:1837-1847. [PubMed: 9603539]

14. Rossouw JE, Prentice RL, Manson JE, Wu L, Barad D, Barnabei VM, Ko M, LaCroix AZ, Margolis KL, Stefanick ML. Postmenopausal hormone therapy and risk of cardiovascular disease by age and years since menopause. JAMA. 2007; 297:1465-1477. [PubMed: 17405972]

\section{APPENDIX: SHORT LIST OF WHI INVESTIGATORS}

Program Office: (National Heart, Lung, and Blood Institute, Bethesda, Maryland) Elizabeth Nabel, Jacques Rossouw, Shari Ludlam, Linda Pottern, Joan McGowan, Leslie Ford, and Nancy Geller.

Clinical Coordinating Center: (Fred Hutchinson Cancer Research Center, Seattle, WA) Ross Prentice, Garnet Anderson, Andrea LaCroix, Charles L. Kooperberg, Ruth E. Patterson, Anne McTiernan; (Wake Forest University School of Medicine, Winston-Salem, NC) Sally Shumaker; (Medical Research Labs, Highland Heights, KY) Evan Stein; (University of California at San Francisco, San Francisco, CA) Steven Cummings. 
Clinical Centers: (Albert Einstein College of Medicine, Bronx, NY) Sylvia WassertheilSmoller; (Baylor College of Medicine, Houston, TX) Jennifer Hays; (Brigham and Women's Hospital, Harvard Medical School, Boston, MA) JoAnn Manson; (Brown University, Providence, RI) Annlouise R. Assaf; (Emory University, Atlanta, GA) Lawrence Phillips; (Fred Hutchinson Cancer Research Center, Seattle, WA) Shirley Beresford; (George Washington University Medical Center, Washington, DC) Judith Hsia; (Los Angeles Biomedical Research Institute at Harbor- UCLA Medical Center, Torrance, CA) Rowan Chlebowski; (Kaiser Permanente Center for Health Research, Portland, OR) Evelyn Whitlock; (Kaiser Permanente Division of Research, Oakland, CA) Bette Caan; (Medical College of Wisconsin, Milwaukee, WI) Jane Morley Kotchen; (MedStar Research Institute/ Howard University, Washington, DC) Barbara V. Howard; (Northwestern University, Chicago/Evanston, IL) Linda Van Horn; (Rush Medical Center, Chicago, IL) Henry Black; (Stanford Prevention Research Center, Stanford, CA) Marcia L. Stefanick; (State University of New York at Stony Brook, Stony Brook, NY) Dorothy Lane; (The Ohio State University, Columbus, OH) Rebecca Jackson; (University of Alabama at Birmingham, Birmingham, AL) Cora E. Lewis; (University of Arizona, Tucson/Phoenix, AZ) Tamsen Bassford; (University at Buffalo, Buffalo, NY) Jean Wactawski-Wende; (University of California at Davis, Sacramento, CA) John Robbins; (University of California at Irvine, CA) F. Allan Hubbell; (University of California at Los Angeles, Los Angeles, CA) Howard Judd; (University of California at San Diego, LaJolla/Chula Vista, CA) Robert D. Langer; (University of Cincinnati, Cincinnati, OH) Margery Gass; (University of Florida, Gainesville/Jacksonville, FL) Marian Limacher; (University of Hawaii, Honolulu, HI) David Curb; (University of Iowa, Iowa City/Davenport, IA) Robert Wallace; (University of Massachusetts/Fallon Clinic, Worcester, MA) Judith Ockene; (University of Medicine and Dentistry of New Jersey, Newark, NJ) Norman Lasser; (University of Miami, Miami, FL) Mary Jo O'Sullivan; (University of Minnesota, Minneapolis, MN) Karen Margolis; (University of Nevada, Reno, NV) Robert Brunner; (University of North Carolina, Chapel Hill, NC) Gerardo Heiss; (University of Pittsburgh, Pittsburgh, PA) Lewis Kuller; (University of Tennessee, Memphis, TN) Karen C. Johnson; (University of Texas Health Science Center, San Antonio, TX) Robert Brzyski; (University of Wisconsin, Madison, WI) Gloria E. Sarto; (Wake Forest University School of Medicine, Winston-Salem, NC) Denise Bonds; (Wayne State University School of Medicine/Hutzel Hospital, Detroit, MI) Susan Hendrix. 


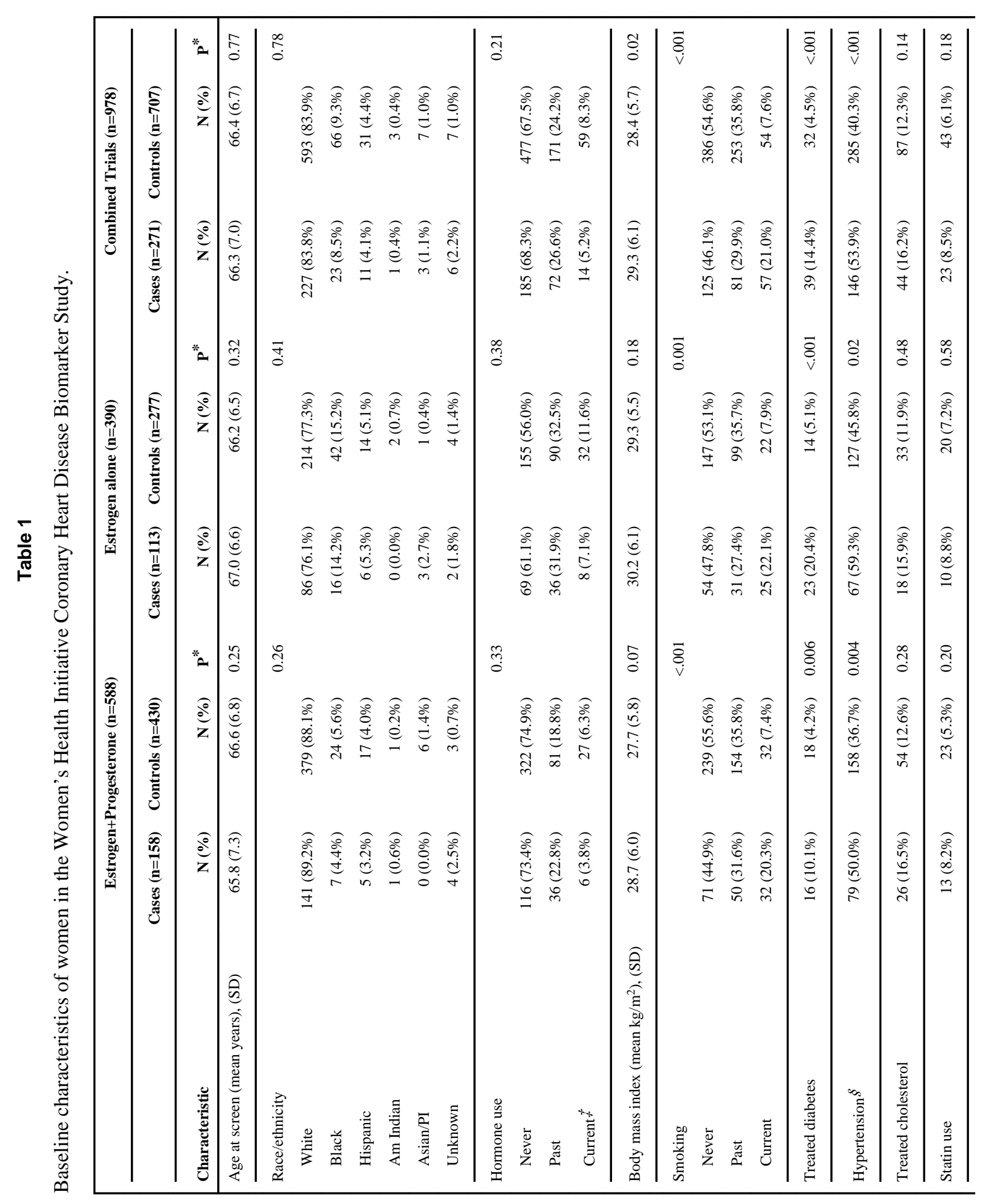




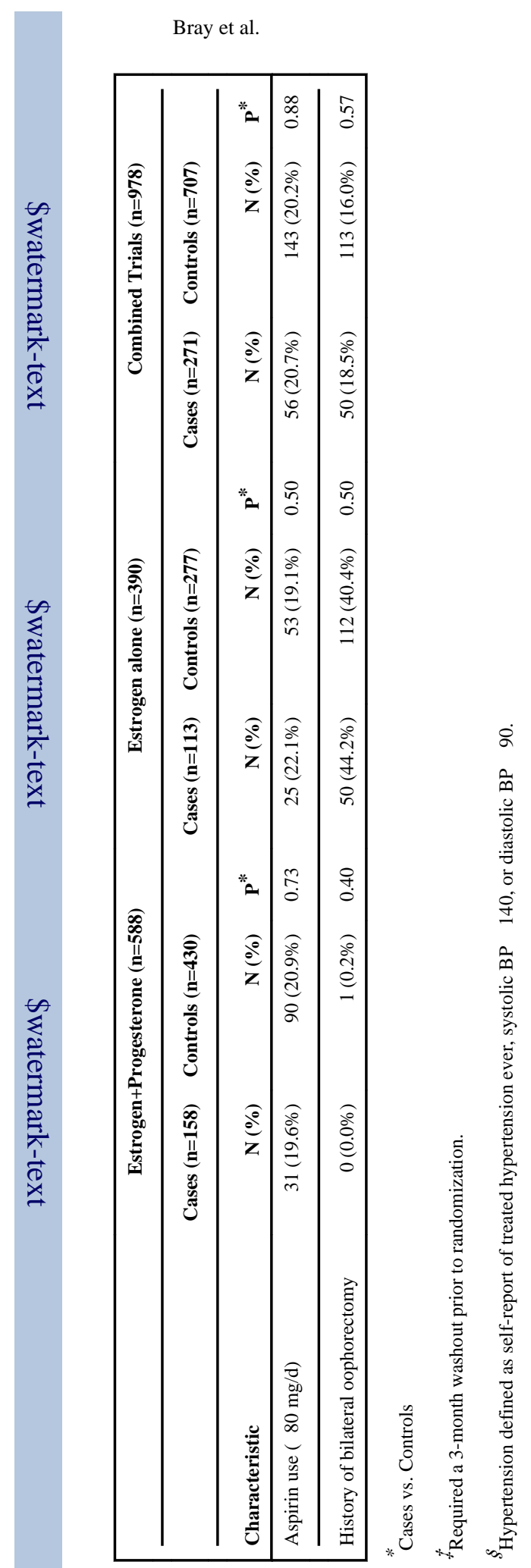

Am J Cardiol. Author manuscript; available in PMC 2013 January 13. 


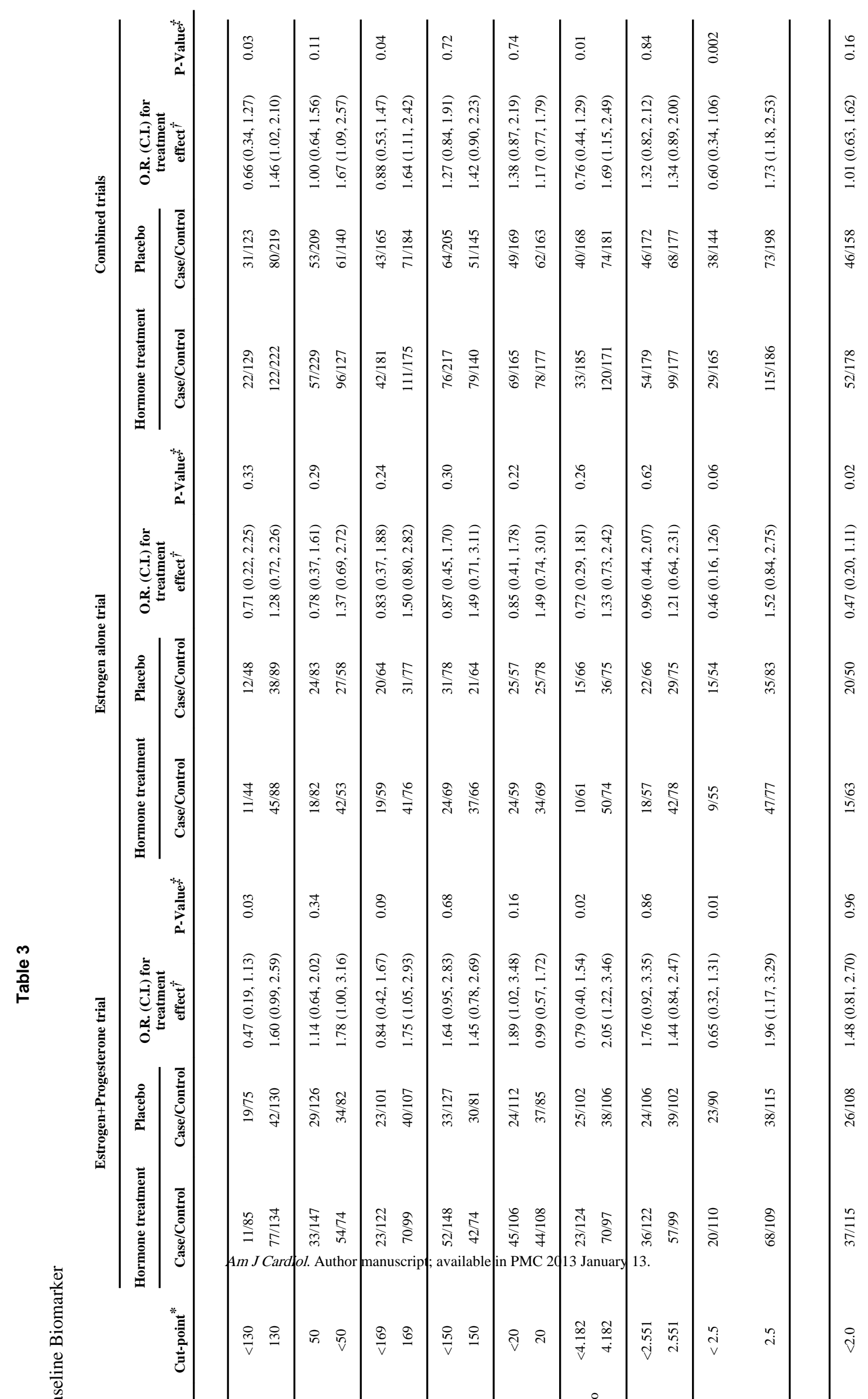




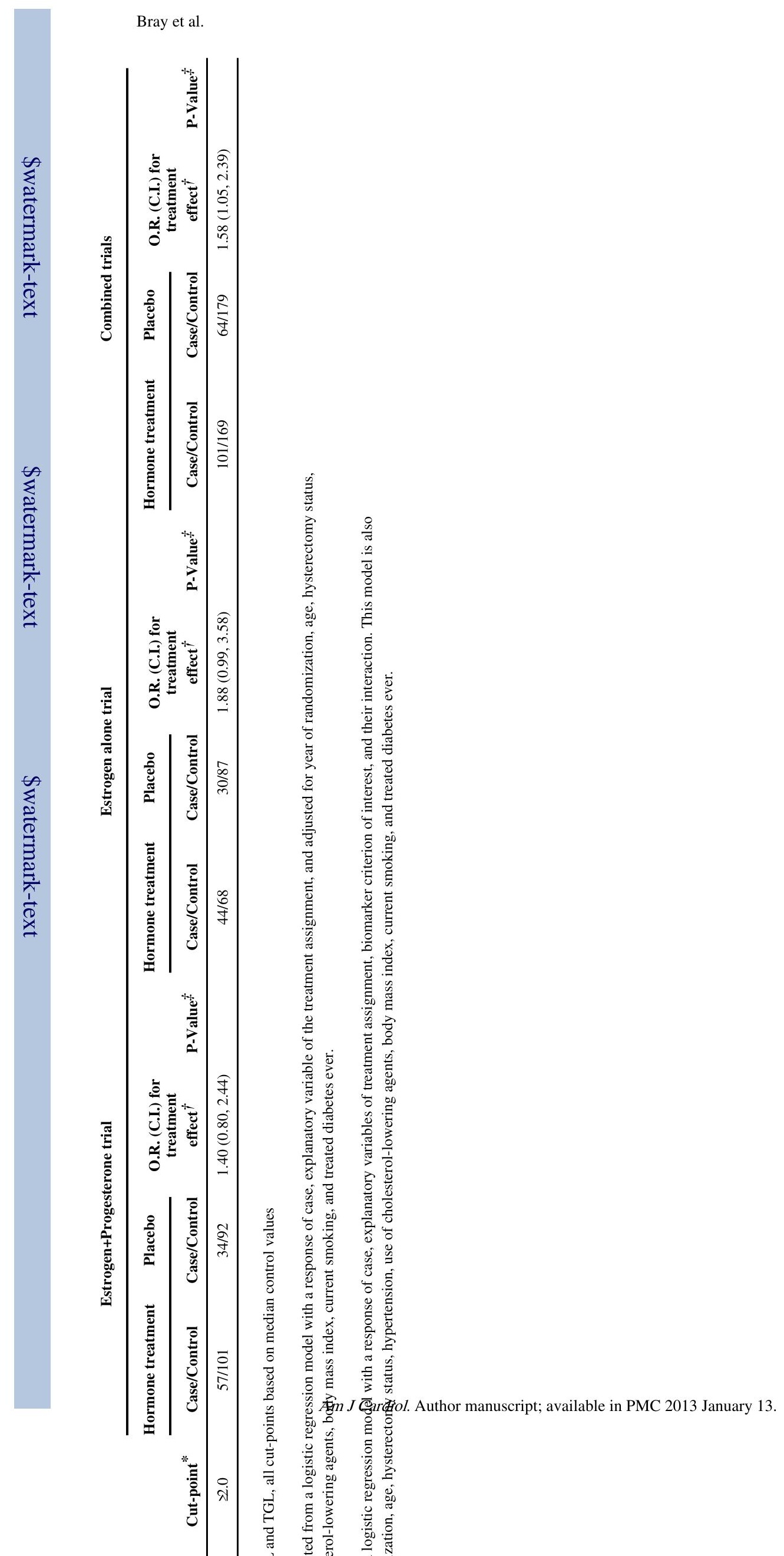

Page 12 


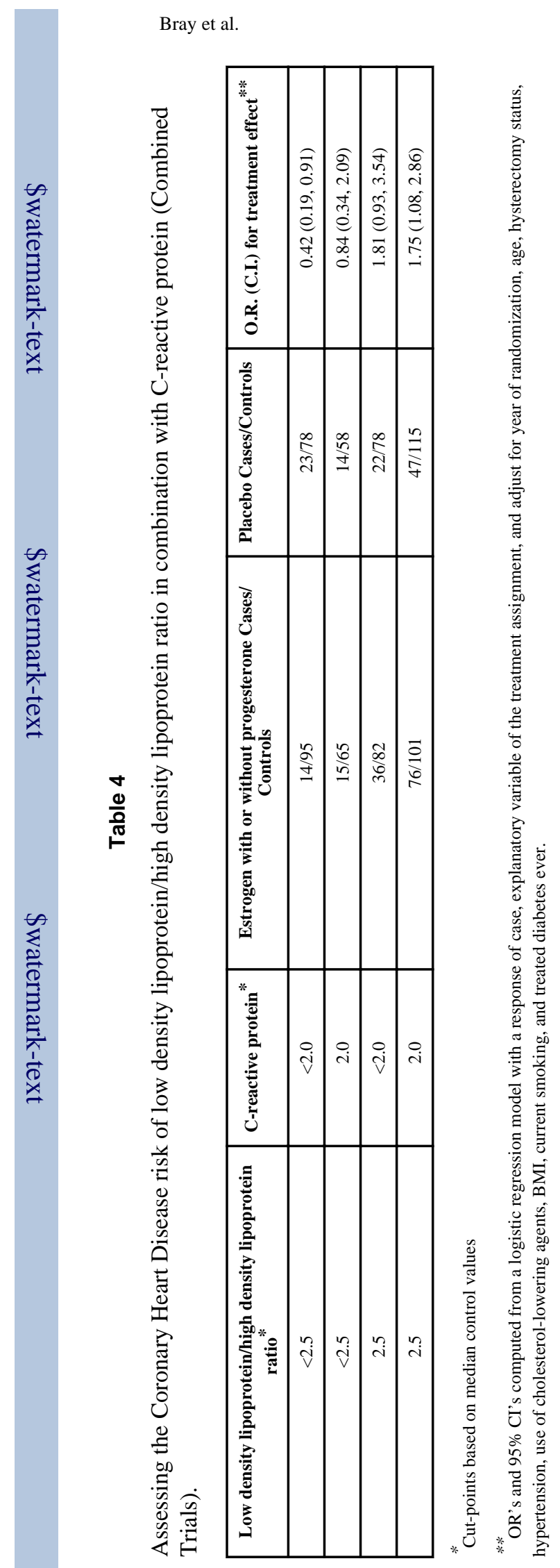

Am J Cardiol. Author manuscript; available in PMC 2013 January 13. 